\title{
DEMOGRAPHIC CHARACTERISTICS OF CHILDREN TREATED UNDER GENERAL ANESTHESIA
}

\author{
Radosveta Andreeva \\ Department of Pediatric Dentistry, Faculty of Dental Medicine, Medical University of Varna
}

\begin{abstract}
General anesthesia is a method of pharmacological behavior management of children.

The aim of this study is to assess the demographic characteristics of children treated under general anesthesia.

Subject of monitoring are 396 children treated under general anesthesia divided into three age groups - up to 5 years; between 6 and 12 years, and from 12 to 18 years. Three periods of time: 2015 - 2016, 2016 - 2017, and 2017 - 2018 were studied. The relative share of girls and boys, the number of treated children from Varna and other regions, and the mean age of children treated under general anesthesia were calculated.

RESULTS: Girls treated under general anesthesia were fewer than boys in the three studied periods of time, with a relative share of $34 \%(n=133)$. The distribution by studied periods was as follows: $n=10(8 \%)$ for the period 2015-2016, $n=30$ (23\%) for the period 2016-2017, $n=93(69 \%)$ for the period 2017-2018. The mean age of the patients involved was $4.86 \pm 3.27$ years. Most of the surveyed population $n=198(50.12 \%)$ belonged to the youngest age group (1-5 years). The second age group (6-12) included 167 (42.27\%) of the children surveyed and only $31(7.6 \%)$ were over 12 years of age.

CONCLUSION: The number of children treated under general anesthesia, both boys and girls, increased with each passing year. For the period 2016-2017, the number of these children was 2.5 times higher than in the previous period and about three times lower than the next (2017-2018).
\end{abstract}

Keywords: general anesthesia, demographic characteristics, mean age

Address for correspondence:

Radosveta Andreeva

Faculty of Dental Medicine

84 Tzar Osvoboditel Blvd

9000 Varna

e-mail:doctor_ra@abv.bg

Received: June 20, 2018

Accepted: July 18, 2018

\section{INTRODUCTION}

Treatment under general anesthesia (GA) is a well-established method of pharmacological behavior management. Some authors indicate that in the Western world, the demand for treatment under general anesthesia in children has been growing (3-5). Children are indicated to dental treatment under GA for various reasons including very young age of the child, fear of a dental procedures, uncooperative behavior, complex medical/physical/mental conditions, a need for extensive treatment, and others. The child's parents greatly appreciate general anesthesia as a treatment modality $(1,2)$ as it significantly im- 
proves the oral health-related quality of life of young children and has a positive impact on their families $(3,4)$.

\section{AIM}

The aim of this study is to assess the demographic characteristics of children treated under general anesthesia.

\section{MATERIALS AND METHODS}

Object of this study were 396 children treated under GA divided into three age groups - up to 5 years, between 6 and 12 years, and from 12 to 18 years. Three periods of time: 2015-2016, 2016-2017, and 2017- 2018 were observed. The study was based on the medical documents filled in for every child treated under general anesthesia. The relative shares of girls and boys, the number of treated children from Varna and other regions, and the mean age of children treated under GA were calculated.

\section{RESULTS AND DISCUSSION}

Girls treated under general anesthesia were fewer than boys in the three studied periods of time. Their relative share was $34 \%(n=133)$; the relative share for the studied period 2015-2016 was $8 \%$ $(\mathrm{n}=10) ; 23 \%(\mathrm{n}=30)$ - for the period 2016-2017, and $69 \%(n=93)$ - for the period 2017-2018. For the boys these percentages were as follows: $8 \%(n=24)$ for the first studied period; $25 \%(n=57)$ - for the second pe- riod, and $67 \%(\mathrm{n}=182)$ - for the last studied period. In total, the relative share of boys treated under general anesthesia was $66 \%(n=263)$ (Table 1$)$.

In some scientific articles the results are similar (5). Another study conducted in Australia, which involved the use of day stay GA for the provision of dental treatment to children, showed no significant difference in the sex ratio of the patients (6).

The mean age of the patients involved was $4.86 \pm 3.27$ years. Our results differ from these of other authors from Jordan, where a higher average age is given (the mean age of females was $6.55 \pm 3.19$ and that of males was $5.76 \pm 3.02)(3,7)$. Most of the surveyed population $\mathrm{n}=198(50.12 \%)$ belonged to the first age group (1-5 years). The second age group (612) included $167(42.27 \%)$ of the children surveyed and only 31 (7.6\%) were over 12 years of age. Our results are similar to other published in the literature $(2,8)$.The number of cases of dental treatment of children under general anesthesia has increased over the years for both genders: from 34 for the period 2015 2016 to 87 for the period 2016-2017, and up to 274 for the last period 2017-2018. This increase is particularly pronounced in the group of children up to the age of 5, which in 2015-2016 were only 15 and in the period 2017-2018 increased to 132. An increasing number of children treated under GA was also reported by other authors $(6,9,10)$.

Table 1. Distribution and percentages of the examined children based on demographic characteristics - gender, residence, and age

\begin{tabular}{|c|c|c|c|c|}
\hline Period & $2015-2016(\%)$ & $2016-2017(\%)$ & 2017-2018 (\%) & Total (\%) \\
\hline \multicolumn{5}{|l|}{ Gender } \\
\hline Boys & $\mathrm{n}=24(8 \%)$ & $\mathrm{n}=57(25 \%)$ & $n=182(67 \%)$ & $n=263(66 \%)$ \\
\hline Girls & $\mathrm{n}=10(8 \%)$ & $n=30(23 \%)$ & $\mathrm{n}=93(69 \%)$ & $n=133(34 \%)$ \\
\hline \multicolumn{5}{|l|}{ Residence } \\
\hline Varna - town & $n=33(12.7 \%)$ & $\mathrm{n}=61(23.64 \%)$ & $n=164(63.56 \%)$ & $\mathrm{n}=258(65.31 \%)$ \\
\hline $\mathrm{V}$ arna region & $\mathrm{n}=1(0.72 \%)$ & $\mathrm{n}=26(18.97 \%)$ & $\mathrm{n}=110(80.29 \%)$ & $\mathrm{n}=137(34.68 \%)$ \\
\hline Mean age (y) & $5.075 \pm 3.08$ & $4.42 \pm 3.01$ & $5.07 \pm 3.72$ & $4.86 \pm 3.27$ \\
\hline \multicolumn{5}{|l|}{ age groups } \\
\hline$<5$ & $\mathrm{n}=15(7.57 \%)$ & $\mathrm{n}=51(25.76 \%)$ & $\mathrm{n}=132(66.67 \%)$ & $\mathrm{n}=198(50.12 \%)$ \\
\hline $5-12$ & $\mathrm{n}=18(10.78 \%)$ & $\mathrm{n}=32(19.16 \%)$ & $\mathrm{n}=116(70.05 \%)$ & $\mathrm{n}=166(42.27 \%)$ \\
\hline$>12$ & $\mathrm{n}=1(3.33 \%)$ & $\mathrm{n}=4(13.33)$ & $n=27(83.33 \%)$ & $n=31(7.6 \%)$ \\
\hline Total (n) & $\mathrm{n}=34$ & $\mathrm{n}=87$ & $\mathrm{n}=274$ & $\mathrm{n}=395$ \\
\hline
\end{tabular}


Most of the children, treated under general anesthesia, were from the town of Varna. Their total relative share was $65.31 \%(n=258)$. For the three studied periods the relative share of patients from Varna was as follows: $12.7 \%(\mathrm{n}=33)$ for the first period; $23.64 \%(n=61)$ for the second period, and $63.56 \%$ $(n=164)$ for the third period. The number of patients from the environs of Varna was lower, compared to that from the town itself, but also increased with the time: $0.72 \%(n=1)$ - for the first period; $18.97 \%(n=26)$ - for the second period, and $80.29 \%(n=110)$ - for the last period. Their total relative share was $34.68 \%$ $(n=137)$.

\section{CONCLUSION}

The number of children treated under GA, both boys and girls, increased with each passing year. For the period 2016-2017 the number of these children was 2.5 times higher than the previous period, and about three times lower than the last period - 20172018. Most of the children treated under GA were about 5 years old.

\section{REFERENCES}

1. Chen YP, Hsieh CY, Hsu WT, Wu FY, Shih WY.

A 10-year trend of dental treatments under general anesthesia of children in Taipei Veterans General Hospital. J Chin Med Assoc. 2017 Apr;80(4):262268. doi: 10.1016/j.jcma.2016.11.001.

2. Holt RD, Chidiac RH, Rule DC. Dental treatment for children under general anesthesia in day care facilities at a London dental hospital. Br Dent J. 1991; 170(7):262-6.

3. Bello LL. A retrospective study of pediatric dental patients treated under general anesthesia. Saudi Dent J. 2000; 12(1):10-5.

4. Savanheimo N, Sundberg SA, Virtanen JI, Vehkalahti MM.. Dental care and treatments provided under general anesthesia in the Helsinki Public Dental Service. BMC Oral Health. 2012; 12:45. doi: 10.1186/1472-6831-12-45.

5. Wang YC, Huang GF, Cheng YJ, Chen HM, Yang $\mathrm{H}$, Lin $\mathrm{CP}$, et al. Analysis of clinical characteristics, dental treatment performed, and postoperative complications of 200 patients treated under general anesthesia in a special needs dental clinic in northern Taiwan. J Dent Sci. 2015; 10(2):172-5. doi: 10.1016/j.jds.2014.06.003.
6. Alcaino E, Kilpatrick NM, Smith ED. Utilization of day stay general anaesthesia for the provision of dental treatment to children in New South Wales, Australia. Int J Paediatr Dent. 2000; 10(3):206-12.

7. Basma K, Fuad H. Dental management for pediatric patients under general anesthesia at Queen Rania hospital for children in Jordan. J Royal Med Services. 2015;22:78.

8. Al-Malik MI, Al-Sarheed MA. Comprehensive dental care of pediatric patients treated under general anesthesia in a hospital setting in Saudia Arabia. J Contemp Dent Pract. 2006; 7(1):1-9.

9. American Academy of Pediatric Dentistry. Policy on early childhood caries (ECC): Classifications, consequences, and preventive strategies. 2011; 35(6):13-4.

10. Vinckier F, Gizani S, Declerck D. Comprehensive dental care for children with rampant caries under general anesthesia. Int J Paediatr Dent. 2001; 11(1):25-32. 